\title{
Het researchcentrum voor onderwijs en arbeidsmarkt
}

Citation for published version (APA):

Heijke, J. A. M. (1986). Het researchcentrum voor onderwijs en arbeidsmarkt. Researchcentrum voor Onderwijs en Arbeidsmarkt, Faculteit der Economische Wetenschappen. ROA Reports No. 1 https://doi.org/10.26481/umarep.1986001

Document status and date:

Published: 01/01/1986

DOI:

10.26481/umarep.1986001

Document Version:

Publisher's PDF, also known as Version of record

\section{Please check the document version of this publication:}

- A submitted manuscript is the version of the article upon submission and before peer-review. There can be important differences between the submitted version and the official published version of record.

People interested in the research are advised to contact the author for the final version of the publication, or visit the DOI to the publisher's website.

- The final author version and the galley proof are versions of the publication after peer review.

- The final published version features the final layout of the paper including the volume, issue and page numbers.

Link to publication

\footnotetext{
General rights rights.

- You may freely distribute the URL identifying the publication in the public portal. please follow below link for the End User Agreement:

www.umlib.nl/taverne-license

Take down policy

If you believe that this document breaches copyright please contact us at:

repository@maastrichtuniversity.nl

providing details and we will investigate your claim.
}

Copyright and moral rights for the publications made accessible in the public portal are retained by the authors and/or other copyright owners and it is a condition of accessing publications that users recognise and abide by the legal requirements associated with these

- Users may download and print one copy of any publication from the public portal for the purpose of private study or research.

- You may not further distribute the material or use it for any profit-making activity or commercial gain

If the publication is distributed under the terms of Article $25 \mathrm{fa}$ of the Dutch Copyright Act, indicated by the "Taverne" license above, 
HET RESEARCHCENTRUM VOOR ONDERWIJS EN ARBEIDSMARKT

$$
\text { ROA-R-1986/ } 1
$$

prof. dr. J.A.M. Heijke

RESEARCHCENTRUM VOOR ONDERWIJS EN ARBEIDSMARKT

Faculteit der Economische Wetenschappen

Rijksuniversiteit Limburg

Maastricht, september 1986 
2. Globale afbakening van het werkterrein

5. Enkele organisatorische aspecten 


\section{KORTE VOORGESCHIEDENIS}

Het vraagstuk van de onderlinge afstemming van het onderwijs en de arbeidsmarkt heeft in het wetenschappelijk onderzoek een in de tijd wisselende belangstelling genoten. In de jaren zestig ging de belangstelling vooral uit naar economische vraagstellingen verbonden aan de bijdrage van het onderwijs aan de economische groei en het rendement van het onderwijs. Daarna verlegde de aandacht zich naar meer sociologisch getinte vraagstukken rond de aansluiting van het onderwijs op de beroepspraktijk, de kwalitatieve verbetering van het werk, in verband met de humanisering van de arbeid, en naar de problematiek rond de inkomensverdeling en de sociale ongelijkheid.

Het zoeken naar nieuwe impulsen voor het tijdens de recessie ernstig verzwakte economisch potentieel ging in de jaren tachtig gepaard met een hernieuwde belangstelling voor het vraagstuk van de bijdrage van het onderwijs aan de economische groei. De nieuwe mogelijkheden voor economische groei hebben voorts geleid tot het weer oplaaien van het debat over de aansluitingsproblematiek, dat gedurende enige tijd door de dalende werkgelegenheid tot rust leek te zijn gekomen. In aansluiting op deze ontwikkeling lijkt het vraagstuk van de humanisering van de arbeid door verbetering van de kwaliteit van het werk, te zijn verschoven naar het doorvoeren van sociale innovaties, die een vergroting van de economische doelmatigheid van het functioneren van bedrijfsorganisaties beogen. De nadruk die thans wordt gelegd op de versterking van het economisch potentieel heeft de vraagstukken rond de sociale en inkomensongelijkheid naar de achtergrond verdrongen.

Meer aandacht valt er voorts te constateren voor de implicaties van de technologische ontwikkeling op het terrein van de automatisering, informatica en biotechnieken voor zowel het onderwijs als de arbeidsmarkt. $\mathrm{Er}$ is ook een grotere belangstelling ont- 
staan voor het keuzeproces binnen het onderwijs en met name voor de afweging van de latere perspectieven op de arbeidsmarkt. Hoewel met onderwijs meer wordt nagestreefd dan alleen de voorbereiding op het latere beroepsleven, worden er plannen ontwikkeld en beproefd welke een structurering van het (beroeps)onderwijs beogen die een betere aansluiting geeft op de eisen en mogelijkheden van de arbeidsmarkt.

Tegen de achtergrond van bovengeschetste ontwikkelingen nam het Ministerie van Onderwijs en Wetenschappen zich voor een opdracht te verstrekken aan de Faculteit der Economische Wetenschappen van de Rijksuniversiteit Limburg (RL) voor de uitvoering van een Project Onderwijs en Arbeidsmarkt. Aan dr. J.A.M. Heijke werd gevraagd als informateur op te treden en de Economische Faculteit nader te informeren over een mogelijke opzet van het project. De opzet van het project zou moeten aansluiten bij zowel de door het Ministerie van Onderwijs en Wetenschappen gevoelde behoeften, als de opzet van het wetenschappelijk onderzoek van de Economische Faculteit van de RL.

Aan de informateur werd verzocht zich in binnen- en buitenland te oriënteren, te inventariseren welk onderzoek in Nederland wordt verricht, na te gaan in hoeverre er interessante buitenlandse voorbeelden zijn en daaruit conclusies te trekken voor een opzet van het project die aan de genoemde eisen voldoet.

De informatie-opdracht werd mei 1985 verstrekt en het informatierapport ${ }^{1)}$ kwam in november van dat jaar gereed. De hoofdconclusie van het rapport luidde dat er duidelijk plaats was voor een instelling die zich op een permanente basis bezighoudt met analyses en prognoses van de (kwantitatieve) ontwikkelingen op de onderwijsmarkt en de arbeidsmarkt, waarbij beide ontwikkelingen met

1) Dr. J.A.M. Heijke, Het Project Onderwijs en Arbeidsmarkt van de Rijksuniversiteit Limburg - informatierapport -, Krimpen aan den IJssel, november 1985. 
elkaar in verband worden gebracht. Bij de definitieve opdrachtverlening van het project, juni 1986, werd deze conclusie overgenomen, in die zin dat het Project Onderwijs en Arbeidsmarkt in ieder geval een informatiesysteem zou moeten opleveren warmee de ontwikkelingen op de arbeidsmarkt kunnen worden weergegeven en waarin de daarvan afgeleide eisen voor het onderwijs tot uitdrukking kunnen worden gebracht. Het te ontwikkelen systeem zou bruikbaar moeten zijn voor de studie- en beroepskeuzevoorlichting aan leerlingen en studenten in respectievelijk het voorgezet en het hoger onderwijs. De opdracht omvat een meerjarige periode, lopend van 1 september 1986 t/m 31 augustus 1991.

In aansluiting op de conclusie van het informatierapport werd door de Economische Faculteit van de RL besloten een centrum op te richten voor onderzoek naar de problematiek van het onderwijs en de arbeidsmarkt: Het Researchcentrum voor Onderwijs en Arbeidsmarkt (ROA). Dit centrum zal organisatorisch worden ingepast in het in oprichting zijnde onderzoeksinstituut van de Economische Faculteit van de RL (LIBER). De onderzoekthema's waarmee het centrum zich wil bezighouden komen overeen met die welke in het informatierapport zijn genoemd. Ze zullen in het vervolg van deze nota worden aangegeven. Getracht zal worden onderzoeksopdrachten te verwerven die bij deze thema's aansluiten, zodat het centrum zichzelf financieel in stand kan houden. De genoemde opdracht van het Ministerie van Onderwijs en Wetenschappen voor de uitvoering van het Project Onderwijs en Arbeidsmarkt vormt de eerste en belangrijkste onderzoeksopdracht van het centrum.

In het volgende zal worden ingegaan op respectievelijk de globale afbakening van het werkterrein van het onderzoekcentrum, de te vervullen taken, de gekozen onderzoekthema's en enkele organisatorische aspecten die zijn verbonden aan het functioneren van het centrum. De te geven beschrijving is in belangrijke mate ontleend aan het informatierapport. 


\section{GLOBALE AFBARENING VAN HET WERKTERREIN}

In het onderzoek naar de problematiek van onderwijs en arbeidsmarkt valt een globale, elkaar overlappende, tweedeling te maken in onderzoek dat op de kwalitatieve aspecten van de relatie onderwijs - arbeidsmarkt is gericht en onderzoek dat de kwantitatieve aspecten van deze relatie tot onderwerp heeft. Bij de kwalitatieve aspecten gaat het om de aansluiting van de in het onderwijs verkregen houding, kennis en vaardigheden op de eisen van de baan, veelal angeduid als de ansluiting onderwijsprogramma - beroepspraktijk. Bij de kwantitatieve aspecten vormt de aansluiting tussen de gevraagde en de aangeboden aantallen personen per categorie van kennis en vaardigheden (opleiding, beroep of functie) onderwerp van onderzoek.

In Nederland houdt men zich relatief sterk bezig met de kwalitatieve aspecten van de aansluitingsproblematiek. In het bijzonder kunnen hier worden genoemd de ontwikkelingsinstituten Stichting voor de Leerplanontwikkeling (SLO) te Enschede en het Pedagogisch Centrum Beroepsonderwijs Bedrijfsleven ( $P C B B$ ) te Den Bosch, en de onderzoeksinstellingen van de TH-Twente en de Katholieke Universiteit Nijmegen. In verhouding hiermee wordt de kwantitatieve problematiek duidelijk onderbelicht. Het Centraal Planbureau makt analyses van de stromen in het onderwijs, zonder deze expliciet te relateren an de arbeidsmarkt. Het Sociaal Cultureel Planbureau heeft zich beziggehouden met de ontwikkeling van de opleidingsstructuur van de werkgelegenheid in de kwartaire sector. Het Nederlands Economisch Instituut heeft een rapport uitgebracht met prognoses op middellange termijn van de ontwikkeling van de arbeidsmarkt naar beroep en opleiding, volgens een praktische onderzoeksbenadering en een globale indeling van beroepen en opleidingen ${ }^{2}$ ).

2) Nederlands Economisch Instituut, Een verkenning van de arbeidsmarkt naar beroep en opleiding tot 1990, OSA-Werkdocument $\mathrm{nr}$. W 17 , januari 1986 . 
In het informatierapport wordt dan ook vastgesteld dat er duidelijk plaats is voor een instelling die zich op een permanente basis bezighoudt met analyses en prognoses van de (kwantitatieve) ontwikkelingen op de onderwijsmarkt en de arbeidsmarkt, waarbij:

I. Beide ontwikkelingen met elkaar in verband worden gebracht.

II. - In principe - het gehele onderwijs en de totale arbeidsmarkt worden bestreken.

III. Zodanige differentiaties worden aangebracht dat een optimale aansluiting met de meer kwalitatieve aspecten van de relatie onderwijs - arbeidsmarkt wordt verkregen.

IV. Naast het uitvoeren van toegepast onderzoek met name aandacht wordt besteed aan de fundamentele onderbouwing daarvan.

Bij de gesprekken die in het kader van het informatie-onderzoek werden gevoerd, werd over het algemeen het belang onderschreven van het opstellen van arbeidsmarktprognoses op middellange termijn met een differentiatie naar beroepen of functies en opleiding. Tegelijkertijd werd echter onderkend dat het opstellen van arbeidsmarktprognoses niet zonder problemen is. Gewezen werd op de geringe voorspelkracht, de zwakke gedragsmatige onderbouwing van de gehanteerde modellen en de grotere flexibiliteit op de arbeidsmarkt dan de gehanteerde indelingen naar deelmarkten suggereren.

Mede hierom is men terughoudend ten aanzien van een rechtstreekse koppeling van de uitkomsten van prognoses aan de planning van onderwijsvoorzieningen. De bestaande onzekerheden tracht men te ondervangen door een zodanige structurering van het (beroeps)onderwijs dat ten eerste het onderwijs sneller kan worden aangepast 
aan de eisen van het bedrijfsleven en ten tweede de door het onderwijs verschafte kennis en vaardigheden de mogelijkheid bieden tijdens het latere beroepsleven in te spelen op nieuwe ontwikkelingen. In dit verband wordt onder meer gestreefd naar een grotere samenwerking met het bedrijfsleven, het uitbouwen van leerlingstelsels en het scheppen van voorzieningen voor herhaalonderwijs. Opgemerkt moet worden dat bij de terughoudendheid ten aanzien van prognoses voor de planning van onderwijsvoorzieningen soms ook gevestigde belangen een rol spelen.

Het opstellen van arbeidsmarktprognoses werd door de informanten positiever bejegend ten aanzien van de informatieve rol die zij kunnen vervullen bij de studiekeuze en de wisseling van beroep. Met de kwaliteit van de huidige informatievoorziening op dit vlak heeft men weinig op. Er bestaat, zo wordt in het informatierapport vastgesteld, duidelijk behoefte aan informatie over de latere kansen op de arbeidsmarkt, de inhoud van de te vervullen beroepen, de uitwaaieringsmogelijkheden, de carrièreperspectieven en de beloning. 


\section{TE VERVULLEN TAREN}

De gevoerde informatiegesprekken en de aanhaking van het project aan de Economische Faculteit van de RL hebben tot de conclusie geleid een duidelijk accent aan te brengen in de activiteiten van het Researchcentrum voor Onderwijs en Arbeidsmarkt (ROA). Besloten is het analyseren van vraagstukken met betrekking tot de onderlinge afstemming van het onderwijs en de arbeidsmarkt en het analyseren en prognosticeren van de ontwikkelingen op de onderwijsmarkt en de arbeidsmarkt, beide in relatie tot elkaar, als de centrale taak van het centrum te zien. Door deze accentlegging kan worden voorzien in de gebleken behoefte aan meer informatie over de ontwikkelingen op de arbeidsmarkt in relatie tot die in het onderwijs, kan voldoende wetenschappelijk gezag worden opgebouwd en wordt de mogelijkheid geboden voor theoretische verdieping en cumulatie van kennis. Deze accentlegging en globale terreinafbakening hebben tot gevolg dat het informeren over de (kwantitatieve) ontwikkeling op de arbeidsmarkt en in het onderwijs als tweede taak van het centrum zou kunnen worden beschouwd.

Door het gelegde accent zullen de overige activiteiten van het centrum worden vervuld vanuit de centraal gestelde taak en de daaraan gekoppelde terreinafbakening. Dit wil zeggen een vervulling indien en voorzover deze van belang is voor of voortvloeit uit de vervuliing van de centrale taak van het project: het uitvoeren van analyses en het opstellen van prognoses. Hierdoor zou bijvoorbeeld het ontwikkelen van leerprogramma's als onderzoekterrein afvallen. Op dit terrein zijn evenwel reeds een aantal gekwalificeerde onderzoekinstituten en ontwikkelingsinstellingen werkzaam, die ook internationaal goed staan aangeschreven. Wel moet worden gestreefd naar een goede aansluiting van het onderzoek op het ontwikkelingswerk.

Een vraagstuk dat eveneens buiten het werkterrein zou komen te liggen is dat van de optimale institutionele structuur van het 
(beroeps)onderwijs en de gewenste infrastructuur ter versterking van de band tussen onderzoek, ontwikkelingswerk en beleid.Vragen met betrekking tot de gewenste institutionele en infrastructurele veranderingen vormen het werkterrein van beleidsinstanties en belangengroepen. Binnen het kader van de gemaakte terreinafbakening voor het centrum zou men evenwel informatie kunnen verschaffen voor het maken van zo rationeel mogelijke keuzen op dit terrein en het aangeven van de gevolgen van genomen beslissingen voor de afstemming van onderwijs en arbeidsmarkt.

Aan de uitvoering van de centrale taak van het centrum zijn inventariserende activiteiten verbonden. De inventarisatie zal mede omvatten het onderzoekwerk dat elders, in binnen- en buitenland, op het werkterrein van het centrum wordt verricht. Het eigen onderzoek en de inventarisatie van wat elders gebeurt zullen de basis moeten verschaffen voor de vervulling van de genoemde informatietaak. Er zou naar een zodanige opzet moeten worden gestreefd dat, al dan niet op verzoek, een min of meer compleet en gedifferentieerd beeld kan worden verschaft van de ontwikkelingen die zich op middellange en lange termijn zullen of kunnen voordoen met betrekking tot (de onderlinge afstemming van) het onderwijs en de arbeidsmarkt. Hiervoor zal het nodig zijn documentatie en informatie te verzamelen op basis van een op te zetten netwerk van nationale en internationale contacten. In aanvulling hierop kan worden gedacht aan het scheppen van allerlei voorzieningen in de publicitaire sfeer, die zijn toegespitst op de potentiële groep gebruikers van de te verschaffen informatie.

Overwogen is het centrum ook een coördinatietaak te laten vervullen. Een dergelijke taak roept evenwel enkele vraagtekens op. Andere instellingen zullen aan een oproep om bepaalde lacunes in het onderzoek en het ontwikkelingswerk in te vullen pas gevolg geven als zij daar belang in zien. Voor zover dit belang van professionele aard is, zal het centrum over voldoende wetenschappe- 
lijk gezag moeten beschikken om anderen te kunnen overtuigen. Aan het bereiken van een hoge wetenschappelijke status gaat evenwel een proces vooraf, waarin men via het verrichte onderzoekswerk nationale en internationale erkenning zal moeten zien te verwerven.

Naast het professionele belang is er het financiële belang. Het moet voor anderen financieel mogelijk zijn om de gesignaleerde ontbrekende elementen in het onderzoek of ontwikkelingswerk aan te vullen. Dit heeft tot gevolg dat het centrum over de daarvoor noodzakelijke financiële bronnen zou moeten kunnen beschikken. De vervulling van de coördinatietaak krijgt dan het karakter van de uitvoering van een programma voor onderzoek en ontwikkeling op basis van een daarvoor ter beschikking staand budget. Dit kan evenwel tot een overlapping leiden van de programma's van de svo en de OSA.

De beoogde coördinatietaak (waaronder ook een signalingstaak valt) zal zich daarom tot enkele, meer bescheiden, aanzetten beperken. Hierbij kan worden gedacht aan:

I. Het uitbrengen van rapporten waarin belangrijke ontwikkelingen op het terrein van onderwijs en arbeidsmarkt worden a angegeven.

II. Het organiseren van symposia en andere bijeenkomsten waar zaken betreffende de afstemming van het onderwijs en de arbeidsmarkt die van belang worden geacht, voor het voetlicht worden gebracht en besproken.

III. Het rekening houden bij de eigen werkzaamheden met die van andere instellingen die van belang zijn voor het afgebakende werkterrein van het centrum. Het gat hier om zowel inste1lingen voor onderzoek als die voor coördinatie en gegevensverzameling, zoals respectievelijk het SCP, het $\mathrm{CPB}$, de SVO, de OSA en het CBS. 
Ook het geven van beleidsadviezen wordt als een taak van het centrum gezien. Het geven van beleidsadviezen vergt een afweging van wenselijkheden en mogelijkheden die niet volledig kan steunen op objectieve onderzoeksresultaten en beschikbare wetenschappelijke kennis. Zeker waar het institutionele en infrastructurele zaken betreft zullen subjectieve inschattingen en het afwegen van belangen noodzakelijk zijn. Het onderzoek dat door het centrum wordt uitgevoerd kan zich evenwel richten op:

I. Het aangeven van juist die ontwikkelingen op het specifieke werkterrein van het centrum, welke voor het nemen van beleidsbeslissingen van belang zijn.

II. Het onderzoeken van beleidsvragen met betrekking tot de onderlinge afstemming van het onderwijs en de arbeidsmarkt, nadat deze zijn getransformeerd tot onderzoekbare vraagste1lingen.

III. Het onderzoeken en evalueren van de (mogelijke en waarschijnlijke) gevolgen van te nemen of genomen beleidsmaatregelen met betrekking tot de onderlinge afstemming van het onderwijs en de arbeidsmarkt.

IV. Het op zodanige wijze presenteren van de resultaten van het ver richte onderzoek dat deze toegankelijk zijn voor beleidsinstanties. 


\section{HET ONDERZOEKPROGRAMMA}

Bij de aanvang van het functioneren van het Researchcentrum voor Onderwijs en Arbeidsmarkt (ROA), zal een programma worden ontwikkeld voor de te ondernemen activiteiten en hun spreiding over de tijd, rekening houdend met de nadere prioritering binnen het afgebakende werkterrein, de verkregen onderzoeksopdrachten, het ter beschikking staande budget en het beschikbare personeel. Dit programma zal periodiek worden bijgesteld voor de actuele ontwikkeling en nieuwe inzichten.

In het navolgende zal een globale beschrijving worden gegeven van het werkterrein van het centrum. Het werkterrein is bepaald aan de hand van de opdracht voor het informatie-onderzoek, de gevoerde gesprekken met informanten, de globale opzet van het wetenschappelijk onderzoek van de Economische Faculteit van de RL en het gevoerde overleg met het Ministerie van Onderwijs en Wetenschappen. De beschrijving zelf is hoofdzakelijk ontleend aan het informatierapport.

Het onderzoek van de Economische Faculteit van de RL is opgebouwd rond een drietal aandachtsvelden, die ook de structurering van het gegeven onderwijs bepalen. Deze aandachtsvelden zijn: de economie van de technologische ontwikkeling, de economie van de arbeid en de economie van het overheidsgedrag en van de publieke sector. Deze thema's of aandachtsvelden sporen eveneens met de behoefte, zoals deze in de gevoerde gesprekken naar voren was gekomen, aan meer kwantitatieve informatie over de ontwikkelingen op de arbeidsmarkt in relatie tot het onderwijs, en, omgekeerd, over de ontwikkelingen in het onderwijs in relatie tot de arbeidsmarkt, beide bij voorkeur over een periode van middellange tot lange termijn bezien. Zij sluiten daarenboven ook aan bij enkele andere verlangens, zoals deze door informanten waren geuit met betrekking tot de relatie onderwijs en arbeidsmarkt, de 
economische aspecten van het (beroeps)onderwijs en het beleid dat op deze terreinen wordt gevoerd.

Hoewel de behoefte aan toekomstverkenningen groot is, hadden veel informanten twijfels over de voorspelbaarheid van de desbetreffende ontwikkelingen. Dit heeft onder meer geleid tot terughoudendheid ten aanzien van het gebruik van prognoses voor de planning van onderwijscapaciteiten en tot pogingen het onderwijs zodanig te structureren dat optimaal op onvoorziene ontwikkelingen kan worden ingespeeld. Niettemin blijft een (steeds terugkerende) behoefte aanwezig meer zicht te krijgen op de ontwikkelingen die zich in de toekomst kunnen afspelen, teneinde:

I. Een rationele capaciteitsplanning in het onderwijs te realiseren.

II. Potentiële studenten en abituriënten te informeren over hun (toekomstige) mogelijkheden op de arbeidsmarkt.

III. De inhoud van het onderwijs an te passen aan de toekomstige eisen en mogelijkheden.

IV. Het economisch potentieel zodanig te structureren dat optimaal profijt wordt getrokken van de investeringen in kennis en vaardigheden van de bevolking.

Bovengenoemde onzekerheid leidt er toe bijzondere aandacht te besteden an het fundamentele onderzoek in het te ontwikkelen programma en tot de praktische suggestie om voorzover het uitgevoerde onderzoek toekomstverkenningen betreft deze met een zekere regelmaat te herhalen.

In concreto wordt er naar gestreefd in het te ontwikkelen onderzoekprogramma de volgende thema's op te nemen:

1. De ontwikkeling van de werkgelegenheid naar bedrijfstak, beroep (of functiecategorie) en vereiste kwalificaties, zoals bepaald door de economische ontwikkeling, de ontwikkeling van proces- en produkttechnologieën en bedrijfsorganisatorische veranderingen. 
2. De belangstelling, de toe-, door- en uitstroom van leerlingen in reguliere en bedrijfs(interne) (beroeps)opleidingen, zoals deze mede zijn bepaald door de demografische ontwikkeling, de schoolprestaties, de sociale achtergrond en de verwachtingen ten aanzien van de latere mogelijkheden op de arbeidsmarkt.

3. De discrepanties tussen vraag en aanbod op de arbeidsmarkt, naar kwalificatieniveau en -richting, alsmede de aard, werking en effectiviteit van de coördinatiemechanismen welke vraag en aanbod op de onderscheiden deelmarkten dichter bij elkaar kunnen brengen.

4. De loopbanen van personen met een bepaalde (beroeps)opleiding in relatie tot de eisen welke in de opeenvolgende banen worden gesteld en de wijze waarop deze worden vervuld.

5. De ontwikkelingspatronen over de tijd van bepaalde beroepen en functiecategorieën in relatie tot de benutting van de kennis en vaardigheden van de vervullers van deze beroepen en functies.

6. De betekenis van het (beroeps)onderwijs, en de verkregen kwalificaties voor de aanvaarding, de beloning, de produktiviteit en het vertrek, respectievelijk van en uit de baan.

7. De planning, kosten en effectiviteit van voorzieningen en capaciteiten in het reguliere beroepsonderwijs en bij bedrijfs(interne) opleidingen.

8. De ontwikkeling van adequate datasystemen en -bronnen teneinde het onderzoek naar bovengenoemde thema's te kunnen uitvoeren.

9. De ontwikkeling van adequate classificatiesystemen zodat de via het onderzoek verschafte informatie op elkaar kan worden a angesloten, alsmede op de inrichting van het (beroeps)onderwijs en de ontwikkelde leerprogramma's.

Bij de uitvoering van het programma zal bijzondere aandacht worden besteed aan de definiëring van de gehanteerde begrippen, de differentiatie van de verschafte gegevens en de vorm waarin de verkregen informatie naar buiten wordt gebracht. Er zal een opti- 
male aansluiting worden nagestreefd met de informatiebehoefte van onderwijsinstanties, instellingen voor de arbeidsvoorziening, instellingen voor de ontwikkeling van leerplannen, het bedrijfsleven en de bevolking.

De genoemde onderzoekthema's zullen niet tegelijkertijd worden aangevat. De hiervoor vereiste kennis en onderzoekinstrumenten kunnen slechts geleidelijk worden opgebouwd. Ook de inhoud van de ontvangen meerjarige opdracht van het Ministerie van Onderwijs en Wetenschappen - het Project Onderwijs en Arbeidsmarkt - dwingt tot een nadere keuze uit de genoemde thema's. Voorlopig is de prioriteit gelegd bij de thema's $1 \mathrm{t} / \mathrm{m} 3$ en de thema's 8 en 9. Van deze thema's zal thema 1 (de structuur van de werkgelegenheidsontwikkeling, i.c. het thema van het Project Onderwijs en Arbeidsmarkt) de hoogste prioriteit krijgen en aan de thema's 8 en $9 \mathrm{zal}$ slechts aandacht worden besteed voor zover dit van belang is voor het goed kunnen uitvoeren van de thema's $1 \mathrm{t} / \mathrm{m} 3$.

In het kader van de ontwikkeling van het programma van activiteiten en onderzoek op het terrein van de genoemde thema's zal het volgende moeten worden vastgesteld:

I. De informatiegebruikers waarop men zich wil richten (onderwijsinstanties, arbeidsvoorziening, bedrijfsleven, ontwikkelingsinstellingen, bevolking).

II. De aard van de (kwantitatieve) gegevens waaraan deze gebruikers behoefte hebben (grootheden, kengetallen, toekomstperioden, periodiciteit van de informatie).

III. De vorm waarin voor de desbetreffende gebruikers de informatie moet worden uitgebracht (breed toegankelijk rapport, wetenschappelijk verslag, artikel, brochure, tabellen).

IV. De databestanden welke kunnen worden benut (met name de beroeps- en opleidingsgegevens). 
V. De vereiste en mogelijke differentiaties in de gegevens, alsmede de daarbij aansluitende classificatiesystemen waarmee deze differentiaties kunnen worden aangebracht en de diverse databestanden aan elkaar gekoppeld.

VI. De modellen, systemen en andere analyse-instrumenten waarmee de vereiste gegevens kunnen worden gegenereerd.

VII. De instellingen waarmee moet worden samengewerkt om via bestaande of nog te ontwikkelen publikatievormen de gegenereerde gegevens bij de finale gebruiker te brengen.

VIII. De onderzoekers en instellingen die vanwege hun specifieke deskundigheid, ervaring en beschikbare onderzoekinstrumenten bepaalde delen van het onderzoekprogramma kunnen uitvoeren.

IX. De activiteiten in het coördinatieve vlak (bijeenkomsten waar bepaalde facetten van het programma worden besproken).

$\mathrm{X}$. De begroting en tijdplanning van de uitvoering van het totale programma (het zelf uit te voeren onderzoek, het uit te besteden onderzoek, de coördinatieve activiteiten, de a anschaf en het gebruik van databestanden, aanschaf en beheer van documentatie, de publikatieve activiteiten).

In concreto kan de nadere invulling van het programma betekenen dat regelmatig, bijvoorbeeld tweejaarlijks, toekomstverkenningen worden uitgebracht van de ontwikkelingen op de arbeidsmarkt en in het onderwijs, waarbij beide ontwikkelingen met elkaar in verband zijn gebracht. Hierbij wordt voorlopig gedacht aan de ontwikkelingen op de middellange termijn. Daarnaast zal dan in tussenliggende perioden regelmatig over de voortgang van de werkzaamheden worden gerapporteerd en publikaties worden uitgebracht over meer specifieke onderwerpen die op middellange termijn waarschijnlijk van grote betekenis zullen worden voor de relatie tussen het onderwijs en de arbeidsmarkt. De activiteiten van het centrum zullen, naast de uitvoering van onderzoek, tevens omvatten het ondernemen van een aantal extern 
gerichte activiteiten in het informatieve en coördinatieve vlak, zoals het organiseren van symposia en andere bijeenkomsten waar zaken betreffende de wederzijdse afstemming van het onderwijs en de arbeidsmarkt onder de aandacht worden gebracht en besproken.

Wat betreft de opdracht van het Ministerie van Onderwijs en Wetenschappen is het van belang op te merken dat het Project Onderwijs en Arbeidsmarkt in elk geval een informatiesysteem zal moeten opleveren waarmee (toekomstige) ontwikkelingen op de arbeidsmarkt kunnen worden weergegeven en waarin de daarvan afgeleide eisen voor het onderwijs tot uitdrukking kunnen worden gebracht. Dit systeem zal bruikbaar moeten zijn voor de studie- en beroepskeuzevoorlichting aan leerlingen/studenten in het voortgezet en het hoger onderwijs.

Met betrekking tot de studie- en beroepskeuzevoorlichting wordt gestreefd naar de totstandkoming van geautomatiseerde (informatie) systemen. Het belangrijkste project op dit terrein is het (pilot) project I-SEE, dat in opdracht van de Interdepartementale Stuurgroep Studie- en Beroepskeuzevoorlichting (ISBV) en met financiering van het Ministerie van Sociale Zaken en Werkgelegenheid (SZW) wordt uitgevoerd door Klijnveld Bosboom Hegener. Andere, deels hierbij aansluitende, projecten zijn bijvoorbeeld:

CHOICES (SLO), IBO/MISTRAL (DG Arbvo van het Ministerie van SZW), PAIS en MIDAS. Een groot probleem bij dergelijke systemen blijkt het ontbreken van adequate arbeidsmarktgegevens te zijn. Met het Project Onderwijs en Arbeidsmarkt zal worden getracht in deze lacune te voorzien. Hierdoor zou een vruchtbare samenwerking mogelijk zijn met de genoemde automatiseringsprojecten. Door samenwerking met I-SEE zou een bijdrage kunnen worden geleverd aan een nieuw te ontwikkelen beleidsinstrument, dat in een dringende behoefte voorziet en een breed draagvlak heeft (de Ministeries van $O \& W$, SZW en EZ en de onderwijsinstellingen). 


\section{ENKELE ORGANISATORISCHE ASPECTEN}

Bij de uitvoering van het programma van activiteiten wordt gestreefd naar een tweeledige opzet:

a. De uitvoering van fundamenteel onderzoek ter ondersteuning van het onderzoek dat in het kader van b. wordt uitgevoerd. Het fundamentele onderzoek zal betrekking hebben op de ontwikkeling en toetsing van (nieuwe) theoretische inzichten en de ontwikkeling van modellen en andere analyse-instrumenten. Bij dit onderzoek staat de wetenschappelijke betekenis voorop en het onderzoek zal een hoger risicokarakter dragen;

b. De uitvoering van toegepast (empirisch) onderzoek dat in op dracht van derden wordt verricht en dat tot praktische resu1taten moet leiden. Het gaat hier om het onderzoek dat rechtstreeks moet leiden tot de publikaties zoals deze zijn voorzien in de opdrachtverlening en het te ontwikkelen programma. Dit deel van de werkzaamheden heeft verder betrekking op de activiteiten verbonden aan de opbouw en het beheer van de vereiste databestanden en classificatiesystemen, alsmede de informerende en coördinerende activiteiten en het uit te besteden onderzoek.

Voor een efficiënte uitvoering van de taken van het Researchcentrum voor Onderwijs en Arbeidsmarkt (ROA) is het van belang dat het fundamentele onderzoek ad $a$. en het toegepaste onderzoek ad b. op elkaar worden afgestemd en binnen het kader van één programma worden uitgevoerd. Wat de programmering van het opdrachtonderzoek betreft zal deze ten dele slechts richtinggevend kunnen zijn omdat de aard, de omvang en het tijdstip van nieuwe opdrachten niet vooraf te plannen is.

Het onderzoekprogramma dat zal worden ontwikkeld zal een coherente onderzoekinspanning betekenen op het terrein van de ontwikkelingen op de onderwijsmarkt en de arbeidsmarkt. Deze inspanning 
kan zeer effectief zijn, omdat in het op te stellen programma en de uit te voeren activiteiten een duidelijke profilering is aangebracht door de oprichting van het Researchcentrum voor Onderwijs en Arbeidsmarkt, dat met de ontwikkeling en uitvoering van het programma is belast. Door deze opzet kan het programma een duidelijk gezicht krijgen, zowel naar buiten als naar binnen (de faculteit), en wordt de duurzaamheid beklemtoond.

Het researchcentrum zal bestaan uit een aantal medewerkers die voor gehele of gedeeltelijke werktijd aan het centrum zijn verbonden en die uit de verkregen onderzoekopdrachten worden betaald. Dr. J.A.M. Heijke werd bereid gevonden het centrum te leiden.

Uit oogpunt van een goede coördinatie van het onderzoek en een doelmatig gebruik van beschikbare voorzieningen zal het centrum worden ingepast in het thans in oprichting zijnde onderzoeksinstituut van de Economische Faculteit van de RL (LIBER).

Het is van belang te benadrukken dat met het Researchcentrum voor Onderwijs en Arbeidsmarkt vooral wordt beoogd een functie te vervullen ten aanzien van de externe en interne profilering van een coherent programma van onderzoek en de uitvoering van een aantal extern gerichte activiteiten in het informatieve en coördinatieve vlak. De inpassing in het facultaire onderzoeksinstituut zal daarom vooral betrekking hebben op de organisatie van het centrum en de benutting van voorzieningen; naar buiten zal het centrum onafhankelijk optreden.

Het programma van activiteiten en onderzoek dat zal worden ontwikkeld zal jaarlijks worden bijgesteld. Bij de opstelling van het eerste programma zal worden getracht naast het Ministerie van Onderwijs en Wetenschappen ook andere opdrachtgevers hiervoor te interesseren. 
Wat betreft de begeleiding van de opstelling en uitvoering van het programma wordt gedacht aan twee vormen van begeleiding:

I. Jaarlijkse toetsing van het programma en de toegepaste methoden aan de mening van wetenschappelijke experts.

II. Regelmatig overleg met (ambtelijke) begeleidingscommissies over de werkzaamheden en plannen ten aanzien van de delen van het programma welke door de desbetreffende opdrachtgevers worden gefinancierd. 